\title{
Study on evaluation and control of credit risk of rural supply chain finance
}

\author{
Jia He \\ Economics and Management School, Yibin University, Yibin, 644000, China
}

Keywords: rural supply chain; financial credit risk; risk evaluation; risk control

\begin{abstract}
The development history of China's supply chain finance is short. It still belongs to exploratory business scope of China's commercial banks. Even so, it can still help Chinese rural financial system gain some effective financial support. But, it also has shortcomings, such as credit risk. So, this paper will carry out detailed discussions in allusion to credit risk of rural supply chain. This paper mainly analyzes how to evaluate credit risk of rural supply chain finance and proposes some targeted risk control countermeasures to help commercial banks and supply chain enterprises to better cope with legal and market risks in the process of developing supply chain finance.
\end{abstract}

\section{Foreword}

Supply chain finance refers to financial business innovated and developed by commercial banks in order to meet supply chain management needs. It is a new approach for financing in rural economic development. But, the development of supply chain finance in Chinese rural area is not mature and perfect enough. In particular, credit problem still affects its continuous development and progress. Thus, it is faced with some financial credit risks, such as legal risk and operation risk. So, we must correctly evaluate financial credit risk of rural supply chain. This requires us constructing a corresponding credit risk evaluation mechanism as soon as possible and giving certain control measures according to actual situations of credit risk of rural supply chain finance so as to construct an effective credit risk evaluation system on the basis of accurately evaluating credit risk of supply chain finance, finally provide reliable basis for implementing control methods and promote healthy, stable and long-term development of economy in the rural area.

\section{Concept and mode of supply chain finance}

As a concept in management field, supply chain management is a new management mode. It enters practice and exploration stage after it is officially proposed. Many enterprises introduce this concept and practice it continuously. This also promotes supply chain management theory to continuously become mature and perfect. As supply chain management mode is implemented in multiple fields, it becomes a goods transfer value chain and value-added chain. It can integrate various resources and realize all-win situation. Then, the concept of supply chain finance appears in financial field. This concept comes from logistics banks. When logistics enterprises deliver goods and materials, they have general understanding of upstream and downstream trading enterprises so that logistics enterprises can use self-owned funds or banks' line of credit to extend credit for upstream and downstream enterprises so as to solve insufficient short-term circulating funds.

Supply chain finance is actually a targeted financing mode in allusion to insufficient enterprise credit in rural economic development and insufficient guarantee. It is different from credit rating mode of traditional commercial banks. It innovatively introduces the idea of supply chain transaction rating. So, we can divide supply chain finance into three different modes: confirming storage financing mode, finance-transportation and warehouse mode and accounts receivable financing mode.

\section{Concept and manifestation pattern of credit risk of supply chain finance}

The risks faced by Chinese enterprises in supply chain mainly include the risk of suppliers' supply, 
the risk in logistics distribution process, information risk and financial risk. These risks will impose great influences on enterprise production and operation process and thus lead to relevant credit risk. Suppliers' supply is a general link in whole supply chain management. It has various risks, such as stockout or quality problem. Thus, the whole supply chain will go wrong. Logistics distribution risk in the supply chain mainly refers to instability of the transportation process. Upstream and downstream enterprises may suffer certain impacts. Information flow is the most important link in the whole supply chain. If information transfer goes wrong, information asymmetry will be caused. Besides, information risk in the supply chain will increase. Even the while supply chain will be caught in troubles. In addition, since each link in the supply chain will involve enterprise capital exchange and capital flow operation, once they are mishandled, financial management risk maybe triggered and transfer to upstream and downstream enterprises in the supply chain. In fact, currently, supply chain management in China has gradually achieved integrative management flow. This makes various risks in supply chain finance easily get together so as to trigger credit risk of the whole supply chain finance, seriously affect enterprises' debt paying ability and reduce financial credit.

\section{Several basic features of credit risks of supply chain finance}

Credit risk is different from traditional risk in supply chain finance. The features are as follows:

(1) Abruptness. Commercial banks in supply chain finance will generate unexpected credit risk financing service. This is because enterprise development scale and management level in the supply chain have their respective actual situations. Many enterprises have no standard management and poor technical force. Thus, credit status of these enterprises is poor. All these factors may lead to enterprise operation risk. These risks cannot be predicted and will suddenly appear due to influences and interference of external factors. So, they have certain abruptness. Once they cannot be well controlled, serious consequences will happen.

(2) Fast propagation speed. Credit risk in supply chain finance belongs to the risk which happens in the supply chain. So, it has basic features of the supply chain, i.e. upstream and downstream enterprises of the supply chain will have business connection and generate certain risk propagation under close correlation. The risk propagation speed is very fast. All enterprises in the supply chain will be involved. It is hard for any enterprises in the chain to get rid of risk invasion. This is because supply chain finance is enterprise-cored, and bank financial services are established by focusing on it. So, in case of the credit risk, all enterprises on the chain will be involved. Besides, it is hard to effectively control. Very serious impacts will occur.

(3) Large and far-reaching harm. Since credit risk of supply chain finance involves multiple industries and multiple enterprises, it will give rise to bad impacts to each participant. So, its credit risk is wide and far-reaching. From a long run, incontrovertible huge harm will occur. This is because credit risk of supply chain finance will involve the whole supply chain and generate adverse effects on development of the whole industry. Then, negative effects on the banks providing financing will appear. In particular, huge economic loss will be caused to banks.

\section{Evaluation of credit risk in rural supply chain finance}

The factors influencing credit risk of supply chain finance mainly include enterprise morality, capital resource and capability development. Commercial banks should carefully know and timely master specific circumstances in these aspects and carry out rational and effective evaluation of credit risk in supply chain finance. Then, it is required to further enrich and subdivide the evaluation and construct a scientific, rational and feasible credit risk evaluation system for supply chain finance.

How should we evaluate credit risk in rural supply chain finance? Currently, the main method to evaluate credit risk in rural supply chain finance is principal component analysis method. Such method not just evaluates credit rating indexes of traditional enterprises such as enterprise quality, operation capacity, profitability, debt paying ability, performance, development prospect and 
industry characteristics, but also focuses on and evaluates in detail core industry characteristics, industry risk factor and supply chain operation in supply chain finance. One of the key evaluation items is evaluation of receivable features. It can be changed to evaluate features of payment in advance and inventory features according to different business status. During evaluating different indexes, we should strictly grade each option and calculate correlation coefficient matrix on the basis of initial database. Besides, the final principal component is worked out with the principal component with large variance. If the score further approaches 1 , the credit of the enterprise evaluated is better. Such method is simple and flexible and is commonly used by commercial banks. But, it also has shortcomings. It is subjective and has certain requirement for the rating personnel.

Rural supply chain finance mainly carries out credit extension service for short-term circulating funds. So, it pays more attention to business transactions in the chain, mainly including evaluation of receivables, payment in advance and inventory. The core evaluation article is the guarantee in transaction. Actually, for any commodity and raw material, as long as they can be measured with market value, we can conduct credit rating with security appraisement method, such as VaR. Foreign scholars conduct securitization measurement and evaluation of KMV model, CreditRisk+ model and Creditmetrics model of transaction price. Foreign mature financial market is appropriate. But, the price of some raw materials cannot be gained in China. Besides, the implementation scope of China's asset securitization is very limited. These make it very difficult to gain relevant data. Therefore, we mainly depend on comprehensive grading and rating system of bank credit experts to evaluate credit risk of rural supply chain finance. Even so, we should strive to use foreign advanced model to measure credit risk so as to continuously adjust China's existing financing mode, establish a healthier, mort stable and vigorous commercial bank financing system and provide better financing environment for economic development in China's rural area.

\section{Control measures for credit risk of rural supply chain finance}

Aiming at the above credit risk of rural supply chain finance, we should take certain actions for effective control on the basis of rational evaluation so as to provide a reliable financial environment for supply chain operation in rural area, improve credit rating of rural enterprises and prevent financial credit risk to the largest extent. The specific control measures are as follows:

(1) Construct a risk evaluation system for supply chain finance. To effectively control credit risk of supply chain finance, we should first establish a corresponding evaluation system. So, we should construct a credit risk evaluation system according to globality, practicability, and the principle of combination of quantitative indexes and qualitative indexes. A first-class overall index should be first constructed. Then, the first-class index is divided into three second-level indexes from the perspectives of morality, ability and capital. Then, each second-level index is further decomposed into different third-level indexes to practically complete construction of comprehensive evaluation index system of credit risk of supply chain finance. Then, we should consider multilevel and multi-factor features of comprehensive evaluation system of the credit risk. In addition, it is hard to quantify some indexes. Therefore, we should quantitatively evaluate evaluation index system through multi-level fuzzy comprehensive evaluation so that commercial banks can correctly evaluate various credit risks in practical supply chain finance, make correct selections and promote healthy and stable development of rural supply chain finance.

(2) Construct legal system and information-based system for credit risk of rural supply chain finance. In fact, during preventions of credit risk of Chinese rural supply chain finance, the state and the government encourage financial institutions to provide effective financial services for rural supply chain through multiple ways and guide the development through government interest subsidy and fiscal subsidy. This requires us formulating policies and legal system for modern rural supply chain finance, provide a good environment for supply chain finance, work out specific laws and regulations for rural supply chain finance and set up the center for supply chain finance. Moreover, prevention and control of credit risk of rural supply chain finance should seek solutions from modern technology. It is required to strive to develop financial information system for Chinese rural supply chain, work out informationalizaiton standards for Chinese rural supply chain finance 
so as to realize unblocked financial information and information sharing in rural area and finally achieve information standardization of credit risk of rural supply chain finance. Financial products and industry should be combined and industrial development and standards should be combined to promote healthy economic development in rural area.

(3) Construct risk identification system and risk management culture system for rural supply chain finance. For rural supply chain finance, risk control is the precondition and foundation. We should establish risk identification system on this basis. In the risk identification system, we should set up corresponding customer credit risk identification system, risk identification system for pledged commodities, risk identification system for warehouse receipt of pledged commodities and operating risk identification system so as to practically improve credit risk control of rural supply chain finance. Besides, we also should construct cultural atmosphere for risk prevention and control, improve risk management awareness and enhance communication among supply chain finance enterprises so that each enterprise in rural supply chain can further enhance mutual in-depth cooperation and realize win-win and mutual benefit.

\section{Acknowledgments}

A Project Supported by Scientific Research Fund of Sichuan Provincial Education Department(No. 14SB0196).

\section{References:}

[1] Hu yuefei, Huang Shaoqing, Supply chain finance: background, innovation and concept definition [J]. Journal of Financial Research, 2009(8)

[2] Lei Xiaoqing, An example of UPS commercial service synchronization and its enlightenment on China's supply chain finance [J]. Logistics Sci-tech, 2011(5)

[3] Li Jinlong, Song Zuoling, Li Yongzhao, Yu Peiyou, Theory and practice of supply chain finance [M]. Beijing: China Communications Press, 2011

[4] Wu Geshan, Credit risk management research based on supply chain finance [J]. Manager Journal, 2009(22)

[5] Xiong Xiong, Ma Jia, Zhao Wenjia et al., Credit risk evaluation under the mode of supply chain finance [J]. Nankai Business Review, 2009(4) 